
\title{
25 Research Soure \\ Linking Male Reproductive Success to Effort Within and Among Nests in a Co-Breeding Stream Fish
}

\section{Seoghyun Kim}

Colorado State University https://orcid.org/0000-0003-3273-0596

Mevin B. Hooten

Colorado State University

\section{Tanya L. Darden}

South Carolina Department of Natural Resources

Yoichiro Kanno ( $\nabla$ yoichiro.kanno@colostate.edu )

Colorado State University

\section{Research Article}

Keywords: Alternative tactics, cooperation, competition, fitness, Nocomis

Posted Date: September 8th, 2021

DOl: https://doi.org/10.21203/rs.3.rs-523137/v1

License: (9) This work is licensed under a Creative Commons Attribution 4.0 International License. Read Full License

Version of Record: A version of this preprint was published at Ethology on April 18th, 2022. See the published version at https://doi.org/10.1111/eth.13283. 


\section{Abstract}

Nest construction is an energetically costly behavior displayed by males in many taxa. In some species, males construct nests and co-breed with other males and they may construct multiple nests in a breeding season. However, little is understood about how allocation of effort within and among nests affects male reproductive success. We characterized reproductive effort of male bluehead chub (Nocomis leptocephalus) on nests in an entire breeding season using PIT antennas deployed around nests and linked effort within and among nests to reproductive success, measured by number of offspring assigned genetically to each male, in a small stream in South Carolina, USA. We monitored time spent by a total of 34 males on each of 18 nests during the spawning season in 2017. A Bayesian hierarchical analysis showed that larger males spent more time constructing and maintaining a given nest, and consequently were more reproductively successful than smaller males on the same nest. Combined with aggressive behavior displayed by larger males toward smaller males, this finding suggested that reproductive effort including agonistic interactions within nests was a determinant of reproductive success. In contrast, more males together constructed larger nests, which led to higher reproductive success of members that constructed those nests. Number of nests that male constructed, a measure of effort across nests, was not a predictor of reproductive success, indicating that reproductive success varied among nests due to nest size. Our study showed that male reproductive success was determined by both aggressive and cooperative behaviors in a co-breeding species.

\section{Introduction}

Reproductive success shapes individual life history and population genetics and dynamics (Merilä and Sheldon 2000; Hedrick 2005). Male reproductive success often depends on reproductive effort because they compete with each other for limited resources such as mates and spawning locations (Emlen and Oring 1977; Andersson 1994; Reynolds 1996). However, males cannot indefinitely expend reproductive effort, which is accompanied by current and future costs (Gillooly and Baylis 1999; Gross 2005; Galimberti et al. 2007). Therefore, allocation of reproductive effort is a key topic in behavioral and evolutionary biology, and this has been most frequently investigated in the context of lifetime reproductive success (Merilä and Sheldon 2000; Dubuc et al. 2014). Less is understood about how males allocate reproductive effort within a spawning season to increase reproductive success (e.g., Metz et al. 2007), despite the common pattern that reproductive success varies greatly among males in polygamous mating systems (Andersson 1994; Dubuc et al. 2014).

Nest construction is a common behavior exhibited by males to attract females for mating and provide parental care of the young in aquatic and terrestrial animals (Soler et al. 1998; Gross 2005; Barber 2013). Males typically spend much effort for nest construction and defend their nests solely (Soler et al. 1998; Lehtonen et al. 2007; Bose et al. 2018). But in some species, males build and share nests with other males (Gross 1996; Taborsky 2009; Díaz-Muñoz et al. 2014). This behavior is adaptive because at least some males of a group benefit from increased reproductive success (Sherley 1990; Theuerkauf et al. 2009; Riehl 2012; Stiver et al. 2013). Cooperative males often form a social structure or partition their 
roles (Taborsky 2001; Olson and Blumstein 2010; Koenig and Walters 2015; Hellmann et al. 2020), which leads to individual variation in reproductive success. But the social hierarchy is not readily evident in other species, where males lek or tolerate mutually on a nest (Taborsky 1994, 2009; Stiver et al. 2013; Díaz-Muñoz et al. 2014). In these co-breeding species, the relationship between reproductive success and behavior is elusive. In addition, males of some species build multiple nests in a reproductive season (Friedl and Klump 2000; Sumasgutner et al. 2016; Kim et al. 2020b). Co-breeding males displaying this behavior must allocate their reproductive effort within and among nests. However, its consequences on male reproductive success are little known because characterizing reproductive effort and behavior of multiple males across nests is challenging in the wild.

An array of behavioral mechanisms is potentially available for co-breeding males to increase reproductive success across nests. First, some males may invest more effort in constructing a nest and providing parental care on the nest than other co-breeding males (Sherley 1990; Evans 1997). Variation in reproductive effort at a single nest explains reproductive success among co-breeding males on the nest in some cases (Evans 1997; Theuerkauf et al. 2009) but not in others (Sherley 1990; Szentirmai et al. 2005). Second, co-breeding males may increase reproductive success by building nests of certain characteristics. Nest size is a measure of male reproductive effort and often increases with the number of co-breeding males (Kim et al. 2020a; 2020b). Larger nests subsequently result in higher male reproductive success (Soler et al. 1998; Lehtonen et al. 2007; Barber 2013; Bose et al. 2018). Finally, males may build multiple nests in a single breeding season to increase reproductive success (Friedl and Klump 2000; Sumasgutner et al. 2016). Building multiple nests is a bet-hedging strategy when some nests fail to produce the young (Gross 1996; Koenig and Walters 2015), and co-breeding may facilitate such a strategy as individual males need not expend as much effort as constructing nests alone. Accordingly, reproductive effort of males can be measured within and among nests, but we know little about the relative importance of these behavioral mechanisms as determinants of reproductive success in cobreeding males.

In this study, we address this knowledge gap by characterizing behavior of uniquely marked males on nests in an entire breeding season and their reproductive success (i.e., number of offspring). We study bluehead chub (Nocomis leptocephalus) as a representative aquatic species in which males co-breed and construct multiple nests in a breeding season. Males of bluehead chub construct dome-shaped nests by moving thousands of pebbles individually by mouth and arranging pebbles to provide parental care for up to 15 days after mating occurs (Wallin 1989, 1992). This signifies much effort expended for reproduction by this small-bodied fish species, where mature males range in body size between 70 and 200 mm (Lanchner 1952; Jenkins and Burkhead 1994). We investigated whether male reproductive success could be explained by (1) relative effort on nest construction and parental care among cobreeding males at each nest, measured by time spent by each co-breeding male at the nest, (2) nest size, an index of effort to move and arrange pebbles, and (3) number of nests males constructed in a breeding season. Behavior of co-breeding males was quantified using an automated tracking system deployed at nests, and reproductive success of males was inferred by the number of offspring assigned genetically to them through parentage. 


\section{Materials And Methods}

\section{Study species and hypotheses}

Bluehead chub is a freshwater fish native to streams on the Atlantic slope of the southeastern USA (Lanchner 1952; Marcy Jr et al. 2005). They reproduce in spring to early summer (Wallin 1989; Kim and Kanno 2020). Male bluehead chub use pebbles to construct nests with other males, although some males construct nests alone (Wallin 1989; Sabaj et al. 2000; Kim et al. 2020a). Co-breeding males use different parts of a nest by excavating small pits where mating occurs (Wallin 1989; Sabaj et al. 2000). Nests constructed by males are used simultaneously by other species for spawning (i.e., nest associates), and this inter-specific relationship is mutualistic because bluehead chub benefit from the presence of eggs of other species on their nests to reduce mortality of their own eggs by predators (Johnston 1994; Cashner and Bart 2010).

We test three plausible behavioral mechanisms to link male reproductive success to effort within and among nests. First, we hypothesize that co-breeding males do not spend an equal amount of reproductive effort on a given nest, but reproductive effort and hence success increases with male body size. Larger males typically dominate smaller males on the same nest (Taborsky 1994; Hellmann et al. 2020), and this aggressive behavior contributes to part of effort related to nest defense and reproduction. Our second hypothesis is that males reproducing on larger nests are more successful than those on smaller nests. Nest size increases with number of males constructing the nest, and larger nests are visited by more bluehead chub females and nest associates (Kim et al. 2020a; 2020b). Males would benefit from increased encounter rates with females and the presence of more eggs of nest associates to dilute predation impacts on their own eggs (Silknetter et al. 2019; Kim et al. 2020a). Third, we hypothesize that constructing more nests increases male reproductive success. Spawning of bluehead chub occurs at intervals of several days in a breeding season (Kim and Kanno 2020), allowing males to construct nests several times in a season. Males stop nest construction and maintenance when abiotic conditions shift abruptly, and pebbles on nests may be dispersed when high stream flows occur due to precipitation (Kim and Kanno 2020; Kim et al. 2020b). This stochastic factor in male reproductive success would favor investment of reproductive effort across nests at different times in a breeding season.

\section{Study area}

This study was conducted in Shoal Creek ( $\left.34^{\circ} 48^{\prime} 12^{\prime \prime} \mathrm{N}, 82^{\circ} 47^{\prime} 02^{\prime \prime} \mathrm{W}\right)$ located in the Savannah River Basin of South Carolina, USA (Appendix S1). We chose an 880-m-long study area (3.1 m wide), where bluehead chub were abundant. Their abundance decreased farther upstream due to small stream size and mixed grazing and residential land use, and farther downstream due to lentic conditions created by beaver (Castor canadensis) dams. Two nest associates were present in Shoal Creek, and yellowfin shiner (Notropis lutipinnis) was more abundant than rosyface chub (Hybopsis rubrifrons).

\section{Field sampling}


Field sampling protocols are detailed in Kim et al. (2020b). Briefly, we marked bluehead chub males with passive integrated transponder (PIT) tags and deployed PIT antennas at nests to record the amount of time each male spent on each nest throughout a breeding season. Later, we collected young-of-the-year (YOY) fish to assign parentage to males using microsatellite markers.

Adult bluehead chub were collected with backpack electrofishing twice before the breeding season (January and April), and three times during the breeding season between May and June 2017. Fish were measured for total length $(\mathrm{mm})$, and genetic samples were taken non-lethally by clipping anal fins. Sex was noted based on secondary characteristics such as tubercles on their head and body colors (Marcy Jr et al. 2015). Individuals $\geq 60 \mathrm{~mm}$ in length were marked by inserting 12-mm half duplex (HDX) PIT tags (Oregon RFID, Portland, OR) into the abdominal cavity. We marked 64 males and 622 females and immature individuals for which sex could not be determined visually.

To monitor nest use by males throughout a breeding season, we visited the study stream daily for 103 consecutive days between 01 April and 12 July 2017 . Mean daily water temperature ranged $12.8-22.3^{\circ} \mathrm{C}$ (mean $=18.3$ ) during this period, and water level was affected by precipitation (Appendix S2). Nests were readily identifiable even after precipitation events because male bluehead chub construct conspicuous pebble mounds and yellowfin shiner spawn in large numbers and display brilliant breeding colors (Fig. 1). Thus, it was highly unlikely to miss nests in our small study stream. After a nest was located, a loopshaped PIT antenna made of copper wire (5.26 $\mathrm{mm}^{2}$ in diameter) was deployed around it to record male identity and time that each male spent on the nest between the beginning of nest construction and cessation of parental care. We monitored up to 6 nests simultaneously using 3 multi-antenna HDX readers (Oregon RFID), and we could not deploy antennas on 3 nests due to technical issues. A total of 18 nests were monitored between 29 April and 23 June, and antennas detected 49 out of the 64 marked males. We used these data to quantify the relative reproductive effort of each male per nest, defined as the number of antenna detections for a male divided by the total number of detections by all males that spawned on the nest. In addition, 15 out of the 49 males detected by antennas visited nests only briefly and their reproductive success could not be genetically confirmed (Kim et al. 2020b). We retained the remaining 34 males (mean total length $=137 \mathrm{~mm}$, range $=103-180$ ) for subsequent analyses. All nests were measured daily for their size (length, width and height) until males stopped attending the nests. Nest size was estimated using the volume of elliptical cone $\left(\mathrm{m}^{3}\right)$, and we used the largest daily measurement at each nest as its size $\left(\right.$ mean $=0.047 \mathrm{~m}^{3}$, range $\left.=0.015-0.116\right)$.

To infer male reproductive success, YOY were collected with backpack electrofishing between 25 August and 10 September 2017. Fin clips were taken for genetic analysis. YOY were sampled in the $880-\mathrm{m}$ study area and an additional 100-m section immediately downstream to collect individuals that might have drifted downstream. However, we did not collect a single YOY individual in the downstream section. A total of 326 YOY were collected ranging in total length between $16-49 \mathrm{~mm}$ (mean $=31 \mathrm{~mm}$ ).

\section{Genetic parentage assignment}


A set of 8 polymorphic microsatellite loci was used for the genetic parentage assignment (Cushman et al. 2020). We genotyped all 49 males and 277 females and immature individuals detected on nests by antennas and 326 YOY for parentage analysis. Females were included to increase accuracy in parentage assignment in program COLONY2 version 2.0.6.5 (Jones and Wang 2010). Paternity was assigned when the assignment probability exceeded $95 \%$. Analytical details can be found in Kim et al. (2020b).

\section{Statistical analysis}

Three sets of regression analyses were conducted to address our study objectives by (1) linking reproductive effort (i.e., proportion of detections) with male body size, (2) comparing effects of size and number of males on nest size, and (3) evaluating how reproductive effort within and among nests affected male reproductive success. Predictors were centered (mean $=0$ and $S D=1$ ), and all analyses were conducted in R version 4.0.1 ( $R$ Development Core Team 2020).

We tested whether larger males spent more reproductive effort than smaller males on a given nest, using a linear mixed-effects model to account for variation among nests. The response was the proportion of antenna detections for each individual at each nest, and the predictor was male body size. We let the intercept and slope vary by nest (i.e., random effects), and nest-specific intercepts and slopes were characterized by conditional normal distributions that accounted for the overall mean and variation across nests. The model was fit using the package Ime4 (Bates et al. 2015), and statistical significance of the overall mean effect of body size on reproductive effort was examined at $a<0.05$ using the package ImerTest (Kuznetsova et al. 2017).

We examined the effects of body size and number of males on nest size using a linear regression model. The response was nest size, and the predictors were the mean size of males and number of males detected on each nest. Statistical significance was identified based on $a<0.05$.

We investigated how reproductive effort within and among nests affected male reproductive success using a hierarchical regression model. This analysis tested whether variation in reproductive success can be explained by male body size, and size and number of nests that males constructed. Reproductive success, or number of offspring, of male $i(i=1, \ldots, 34)$ was modeled as $y_{i} \sim$ Poisson $\left(\lambda_{i}\right)$, where the heterogeneity in intensity was characterized by:

$$
\log \left(\lambda_{i}\right) \sim \operatorname{Normal}\left(x_{i} \beta+\sum_{j=1}^{18} w_{i, j} \alpha_{j}, \sigma^{2}\right) .
$$

In Eq. (1), body size of male $i$ was denoted by $x_{i}$ with its fixed effect $\beta, a_{j}$ referred to random effects of nest $j(j=1, \ldots, 18)$ on which male $i$ spawned, and the conditional variance of intensity, $\log \left(\lambda_{j}\right)$, was denoted by $\sigma^{2}$. Because random effects of nests were accounted for, we tested whether larger males were more reproductively successful than smaller males on a given nest via the fixed effect $\beta$. Furthermore, size of nest $j$ was included to explain nest-level variation in male reproductive success as: 


\section{$\alpha_{j} \sim \operatorname{Normal}\left(\gamma_{0}+z_{j} \gamma_{1}, \sigma_{\alpha}^{2}\right)$}

where $\gamma_{0}$ was the intercept and $\gamma_{1}$ was the fixed effect of nest size $z_{j}$. The $w_{i, j}$ in Eq. (1) expressed the membership of individual $i, j^{\text {th }}$ nest weighted by reproductive effort. Therefore, $w_{i, j}=0$ for a nest $j$ on which individual $i$ did not spawn, otherwise $0<w_{i, j} \leq 1$. This approach explicitly considered nest-level variation in male reproductive success due potentially to nest size, while assuming that reproductive success among males on a given nest is proportional to effort expended by each male. Thus, the hierarchical model tested whether reproductive success was affected by the size and number of nests males constructed and within-nest reproductive effort. The sum of $w_{i, j} a_{j}$ across $J$ nests in Eq. (1) indicated the accumulation of nest random effects weighted by reproductive effort for each male $i$. We evaluated whether the cumulative nest random effects increased due to number of nests that each male visited or the sum of nest size he visited, using post hoc linear regression.

The hierarchical model was fit to our data using a MCMC algorithm with Gibbs updates for all parameters except for $\lambda_{i}$, which had full-conditional distributions that were not conjugate (Hooten and Hefley 2019). We used random walk Metropolis-Hastings updates for $\lambda_{i}$, a standard practice when fitting Bayesian generalized linear models. Relatively flat priors were used for all parameters. We ran the MCMC algorithm for 100,000 iterations and omitted the first 10,000 as burn-in. Effects of male body size $(\beta)$ and nest size $(\gamma)$ on reproductive success were judged statistically significant if $95 \%$ marginal posterior credible intervals $(\mathrm{Cl})$ did not overlap zero.

\section{Results}

Reproductive success was highly variable among males. Of the 34 non-transient males detected on the 18 nests, 15 males were genetically assigned to 169 YOY out of 326 genotyped (52\%). The number of YOY assigned (i.e., reproductive success) ranged 1-33 among males (mean $=10)$. The 15 males with reproductive success ranged $115-172 \mathrm{~mm}$ (mean $=141$ ), and their body size did not differ significantly from the other 19 males without reproductive success (mean $=135 \mathrm{~mm}$; range $=103-180)(t$-test: $t=$ -1.04, $d f=31.62, P=0.31$ ). In general, larger males were detected at nests earlier in the spawning season than smaller males (Spearman's rank correlation test: $\rho=-0.40, P=0.02$ ).

Males constructed an average of 2 nests during the spawning season (range $=1-5$ ). An average of 3 males (range $=1-5$ ) were detected by PIT antennas per nest. The linear mixed-effects model showed that larger males invested more reproductive effort than smaller males on given nests (overall mean effect of body size across nests $=0.44, \mathrm{SE}=0.15, P=0.01$ : Fig. 2 ). Nest size increased when more males constructed together (mean effect $=0.62, \mathrm{SE}=0.21, P=0.01$ : Fig. 3 ), whereas nest size did not increase with male body size (mean effect $=0.05, \mathrm{SE}=0.21, P=0.80$ ).

Similar to male-size-mediated reproductive effort, the hierarchical regression model showed that larger males had higher reproductive success after accounting for variation among nests (posterior mean $\beta=$ 
$0.65,95 \% \mathrm{Cl}=0.23-1.08)$. Male reproductive success also increased with nest size $\left(\gamma_{1}=3.07,95 \% \mathrm{Cl}=\right.$ 1.14-5.08). The cumulative random effects across nests $\left(\sum_{j} w_{i, j} \alpha_{j}\right)$ in Eq. (1) increased significantly with the sum of nest size that males were detected (Pearson correlation test: $r=0.76, P<0.001$ : Fig. $4 a$ ), but did not depend on the number of nests that males constructed $(r=0.25, P=0.15$ : Fig. $4 \mathrm{~b})$. Therefore, nest size is a determinant of male reproductive success, while simply constructing more nests did not

lead to successful reproduction. Finally, the cumulative nest random effects $\left(\sum_{j} w_{i, j} \alpha_{j}\right)$ did not depend on male body size (Pearson correlation test: $r=-0.15, P<0.40$ : Fig. 5), providing further evidence that larger males did not construct larger nests. Taken together, our results suggested that building larger nests with other males increased reproductive success, but once on a given nest, larger males spent more reproductive effort than smaller males and consequently were more successful reproductively.

\section{Discussion}

Our findings supported two of the three hypothesized behavioral mechanisms to increase reproductive success of co-breeding males. Larger males invested more effort on a given nest than smaller males, and consequently were more reproductively successful. Thus, within-nest measures of effort were a correlate of male reproductive success. In addition, male reproductive success varied by nest. Reproductive success was higher for males who constructed larger nests together with more co-breeding males but constructing more nests did not increase reproductive success. These results show that reproductive success of co-breeding males increases due to multiple behavioral mechanisms.

Positive relationships between male body size and reproductive success are commonly reported in cobreeding species (Friedl and Klump 2000; Theuerkauf et al. 2009) and others (Lehtonen et al. 2007; Barber 2013; Bose et al. 2018). Agonistic behavioral interactions occur on nests and their outcomes depend on body size (Soler et al. 1998; Hellmann et al. 2020). Larger males of bluehead chub at times displayed aggressive behavior toward smaller males occupying the same nest in this study (S. Kim, pers. obs.) and others (Wallin 1989; Sabaj et al. 2000; Kim et al. 2020b). Males guarded their own spawning pits aggressively, while other males spawned simultaneously on the same nest by displaying a mutual tolerance as co-breeders (Fig. 1). Sneaking behavior was not observed in bluehead chub (Kim et al. 2020b). Accordingly, larger males did not solely own nests, resulting in positively size-dependent patterns of reproductive effort and success. Bluehead chub are short-lived ( $<3-4$ years) but iteroparous with $2-3$ potential years of spawning (Lanchner 1952; Marcy Jr et al. 2005). Given the few annual opportunities to reproduce, we speculate that larger and presumably older males maximize reproductive effort in the current breeding season, but smaller, younger males balance current reproductive effort and its effects on subsequent survival and reproductive success while subject to the current constraint imposed by larger males due to their agonistic behavior (Taborsky 2001; Gross 2005).

Earlier, we reported that body size of males did not affect their reproductive success in the study stream (Kim et al. 2020b). The discrepancy between the earlier and current studies is likely due to three reasons. First, the current study used a subset of data reported by Kim et al. (2020b) by focusing on males 
detected by PIT antennas at the nests. A total of 64 males were marked with PIT tags between January and June 2017, but only 34 of them were detected on the 18 nests in the current study. We cannot know with certainty the fate of the males not detected by the antennas, whether it is mortality or emigration. It is plausible that body size differently affects reproductive success of males once they are on the nests versus survival during the few months leading up to breeding. Second, the current analysis explicitly accounted for variation in male reproductive success among nests, in contrast to Kim et al. (2020b). The male body size effect on reproductive success is indeed not readily discernable on a biplot (Fig. 5). By incorporating that male reproductive success varies among nests, our current analysis showed that male body size mattered relative to the size of other males on a given nest. Furthermore, our current approach assumed that reproductive success among males on the same nest is partitioned based on their relative effort measured by the time spent on the nest by each male. Third, larger males were detected earlier in the spawning season than smaller males, but Kim et al. (2020b) did not incorporate this seasonal pattern. By incorporating the nest random effect in the hierarchical model, the current analysis was able to account for the seasonal pattern indirectly. Overall, the current result updates our previous knowledge and provides a novel insight that male body size is indeed a predictor of reproductive success among males occupying the same nest.

Perhaps not surprisingly for a co-breeding species, construction of nests with more males led to larger nests and higher reproductive success. It is noteworthy that the 5 most reproductively successful males (range $=13-33$ ) constructed the largest nest. Nest size is an indicator of male quality, thus it influences mate choice and reproductive success in many nest-building species (Soler et al. 1998; Barber 2013; Bose et al. 2018). Likewise, larger nests attracted more female bluehead chub so that males could increase encounter with their potential mates (Kim et al. 2020b). Larger nests were also visited and used for spawning by larger groups of yellowfin shiner in streams nearby, which would dilute predation effects on bluehead chub eggs (Silknetter et al. 2019; Kim et al. 2020a). Because constructing more nests did not increase male reproductive success in the current study, our data indicated that males could best increase reproductive success by constructing certain nests (i.e., larger nests) and spent more effort on those nests.

Our data did not support one hypothesis that constructing more nests would increase male reproductive success. We considered that this behavior would function as a bet-hedging strategy in a stochastic environment where high flows due to precipitation mobilize substrates that make up nests (i.e., nest failures) based on our previous studies (Kim and Kanno 2020; Kim et al. 2020a). In the current study, precipitation was recorded frequently in April (i.e., prior to the onset of the spawning season) but was recorded less frequently afterward (Appendix S2). Perhaps a bet-hedging strategy might be more effective in a hydrologically less stable condition. This idea could be tested in a longer-term study with contrasting summer precipitation regimes (i.e., dry versus wet summers) or in a design that incorporates space-fortime substitution (i.e., free-flowing versus flow-regulated rivers). A longer-term study to keep track of the same individuals in multiple years would also show whether nesting behaviors, such as number of nests to build in a single spawning season and number to males to build nests with, would change through ontogeny. 
We were challenged to analyze this complex data set because the nest from which YOY originated could not be identified via the genetic assignment method, given that males were commonly recorded on multiple nests by the PIT antennas. An alternative approach would have been to collect eggs from nests (Silknetter et al. 2019). This requires lethal sampling and is logistically difficult because eggs of nest associates outnumber greatly those of bluehead chub on nests (Cashner and Bart 2010; Silknetter et al. 2019). We also experimentally tested the effect of male body size on reproductive success, but with equivocal results (Kim 2019), reflecting the difficulties of controlling body size and number of males in a manipulative experiment in the wild. Sampling YOY in the current study integrates nest origin and survival in the subsequent few weeks, an approach suitable for measuring animal reproductive success (Westneat and Fox 2010). Ultimately, we devised a model-based solution by accounting explicitly for memberships of males to nests and reproductive effort of each male relative to others on each nest.

In conclusion, effort within nests was a stronger determinant of male reproductive success than effort among nests. This within-nest effort consisted of larger males spending more effort than smaller nests often accompanied by agonistic interactions, and more males building larger nests together. Coexistence of these two seemingly different mechanisms, aggression and cooperation, is not a shared behavior among species in genus Nocomis, and indeed this combination of male reproductive behaviors is rare among fishes (Taborsky 1994; 2009). Our study in this unique system demonstrated that aggression and cooperation shaped male reproductive success. This study provides a novel empirical insight on the evolution of mating systems because previous studies predominantly examined only aggression or cooperation (Gross 1996; Soler et al. 1998; Hellmann et a. 2020; but see Díaz-Muñoz et al. 2014).

\section{Declarations}

Acknowledgements This study was supported financially by the Creative Inquiry program for undergraduate research and the College of Agriculture, Forestry, and Life Sciences at Clemson University, and the Warner College of Natural Resources at Colorado State University. We thank Brandon Peoples, Sam Silknetter, William Hobbie, and Dakota Jackson for their assist in the fieldwork, and Kasey Pregler and Elizabeth Cushman for genotyping samples in the laboratory. Lisa Angeloni, Kevin Bestgen, and Dana Winkelman provided for constructive criticisms that improved the manuscript. Any use of trade, firm, or product names is for descriptive purposes only and does not imply endorsement by the U.S. Government.

Author contributions SK and YK conceived the study. SK collected the field data. TLD provided oversight on the collection of genetic data and laboratory analysis. MBH, SK and YK conducted the statistical analysis. YK led writing of the manuscript. All authors approved the final manuscript.

Data availability The datasets used in this study are available from the corresponding author on reasonable request.

\section{Compliance with ethical standards}


Conflict of interest The authors declare that they have no conflict of interest.

Ethical approval All applicable international, national, and/or institutional guidelines for the use of animals were followed. The study was conducted in accordance with procedures approved by the Clemson University Institutional Animal Care and Use Committee (IACUC Protocol Number 2014-047 and 2017-039).

\section{References}

1. Andersson MB (1994) Sexual selection. Princeton University Press, Princeton, NJ, USA

2. Barber I (2013) The evolutionary ecology of nest construction: insight from recent fish studies. Avian Biol Res 6: 83-98. doi: 10.3184/175815513X13609538379947

3. Bates D, Mächler M, Bolker B, Walker S (2015) Fitting linear mixed-effects models using Ime4. J Stat Softw 67: 1-48. doi: 10.18637/jss.v067.i01

4. Bose APH, Cogliati KM, Luymes N, Bass AH, Marchaterre MA, Sisneros JA, Bolker BM, Balshine S (2018) Phenotypic traits and resource quality as factors affecting male reproductive success in a toadfish. Behav Ecol 29: 496-507. doi: 10.1093/beheco/ary002

5. Cashner MF, Bart HL (2010) Reproductive ecology of nest associates: use of RFLPs to identify cyprinid eggs. Copeia 2010: 554-557. doi: 10.1643/CG-09-191

6. Díaz-Muñoz SL, DuVal EH, Krakauer AH, Lacey EA (2014) Cooperating to compete: altruism, sexual selection and causes of male reproductive cooperation. Anim Behav 88: 67-78. doi:

10.1016/j.anbehav.2013.11.008

7. Dubuc C, Ruiz-Lambides A, Widdig A (2014) Variance in male lifetime reproductive success and estimation of the degree of polygyny in a primate. Behav Ecol 25: 878-889. doi:

10.1093/beheco/aru052

8. Emlen ST, Oring LW (1977) Ecology, sexual selection, and the evolution of mating systems. Science 197: 215-223. doi: 10.1126/science.327542

9. Evans MR (1997) Nest building signals male condition rather than age in wrens. Anim Behav 53: 749-755. doi: 10.1006/anbe.1996.0311

10. Friedl TWP, Klump GM (2000) Nest and mate choice in the red bishop (Euplectes orix): female settlement rules. Behav Ecol 11: 378-386. doi: 10.1093/beheco/11.4.378

11. Galimberti F, Sanvito S, Braschi C, Boitani L (2007) The cost of success: reproductive effort in male southern elephant seals (Mirounga leonine). Behav Ecol Sociobiol 62: 159-171. doi:

10.1007/s00265-007-0450-y

12. Gillooly JF, Baylis JR (1999) Reproductive success and the energetic cost of parental care in male smallmouth bass. J Fish Biol 54: 573-584. doi: 10.1111/j.1095-8649.1999.tb00636.x

13. Gross MR (1996) Alternative reproductive strategies and tactics: diversity within sexes. Trends Ecol Evol 11: 92-98. doi: 10.1016/0169-5347(96)81050-0 
14. Gross MR (2005) The evolution of parental care. Q Rev Biol 80: 37-45. doi: 10.1086/431023

15. Hellmann, JK, Stiver KA, Marsh-Rollo, S, Alonzo SH (2020) Defense against outside competition is linked to cooperation in male-male partnerships, Behav Ecol 31: 432-439. doi:

10.1093/beheco/arz206

16. Hedrick $P$ (2005) Large variance in reproductive success and the Ne/N ratio. Evolution 59: 15961599. doi: 10.1111/j.0014-3820.2005.tb01809.x

17. Hooten MB, Hefley TJ (2019) Bringing Bayesian models to life. CRC Press, Boca Raton, Florida, USA. doi: $10.1201 / 9780429243653$

18. Jenkins RE, Burkhead NM (1994) Freshwater fishes of Virginia. American Fisheries Society, Bethesda, Maryland, USA

19. Johnston CE (1994) The benefit to some minnows of spawning in the nests of other species. Environ Biol Fish 40: 213-218. doi: 10.1007/BF00002547

20. Kim S (2019) Intraspecific variation in reproductive ecology and success of keystone stream fish, bluehead chub. PhD dissertation, Colorado State University, Fort Collins, Colorado, USA

21. Kim S, Kanno Y (2020) Spawning periodicity and synchrony of bluehead chub (Nocomis leptocephalus) and a nest associate, yellowfin shiner (Notropis lutipinnis), across local stream. Ecol Freshw Fish 29: 299-310. doi: 10.1111/eff.12515

22. Kim S, Peoples BK, Kanno Y (2020a) Diverse reproductive patterns of Bluehead Chub (Nocomis leptocephalus) and their relationships with nest size and interactions with an associate, Yellowfin Shiner (Notropis lutipinnis). Environ Biol Fish 103: 783-794. doi: 10.1007/s10641-020-00980-x

23. Kim, S, Pregler, KC, Cushman, EL, Darden, TL, Kanno Y (2020b) Behavior outweighs body size in mediating male reproductive success in a nest-building fish, bluehead chub. Behav Ecol Sociobiol 74: 148. doi: $10.1007 /$ s00265-020-02933-x

24. Koenig WD and Walters EL (2015) Temporal variability and cooperative breeding: testing the bethedging hypothesis in the acorn woodpecker. Proc R Soc B 282:20151742. doi: $10.1098 /$ rspb.2015.1742

25. Kuznetsova A, Brockhoff PB, Christensen RHB (2017) ImerTest Package: Tests in Linear Mixed Effects Models. J Stat Softw 82: 1-26. doi: 10.18637/jss.v082.i13

26. Lanchner EA (1952) Studies of the biology of the cyprinid fishes of the chub genus Nocomis of northeastern United States. Am Midl Nat 120: 433-466. doi: 10.2307/2422260

27. Lehtonen TK, Rintakoski S, Lindström L (2007) Mate preference for multiple cues: interplay between male and nest size in the sand goby, Pomatoschistus minutus. Behav Ecol 18: 696-700. doi: 10.1093/beheco/arm032

28. Marcy BC Jr, Fletcher DE, Martin FD, Paller MH, Reichert MJM (2005) Fishes of the Middle Savannah River Basin: with emphasis on the Savannah River site. University of Georgia Press, Athens, Georgia, USA 
29. Merilä J, Sheldon BC (2000) Lifetime reproductive success and heritability in nature. Am Nat 155: 301-310. doi: $10.1086 / 303330$

30. Metz M, Geberzahn N, Hansen LH, Klump GM, Friedl TW (2007) Effects of behavioural time budgets and nest-building efficiency on male reproductive performance in red bishops (Euplectes orix). $\mathrm{J}$ Ornithol 148: 145-155. doi: 10.1007/s10336-006-0111-3

31. Olson LE, Blumstein DT (2010) Applying the coalitionary-traits metric: sociality without cooperation in male yellow-bellied marmots. Behav Ecol 21: 957-965. doi: 10.1093/beheco/arq094

32. R Development Core Team (2020) R: A language and environment for statistical computing. $R$ Foundation for Statistical Computing, Vienna, Austria. https://www.R-project.org/

33. Reynolds JD (1996) Animal breeding systems. Trends Ecol Evol 11: 68-72. doi: 10.1016/01695347(96)81045-7

34. Riehl C (2012) Mating system and reproductive skew in a communally breeding cuckoo: hardworking males do not sire more young. Anim Behav 84: 707-714. doi:

10.1016/j.anbehav.2012.06.028

35. Sabaj MH, Maurikis EG, Woolcott WS (2000) Spawning behaviors in the bluehead chub, Nocomis leptocephalus, river chub, Nocomis micropogon and central stoneroller, Campostoma anomalum. Am Midl Nat 144: 187-201. doi: 10.1674/00030031(2000)144[0187:SBITBC]2.0.CO;2

36. Szentirmai I, Komdeur J, Székely T (2005) What makes a nest-building male successful? Male behavior and female care in penduline tits. Behav Ecol 16: 994-1000. doi: 10.1093/beheco/ari080

37. Silknetter S, Kanno Y, Kanapeckas Métris KL, Cushman EL, Darden TL, Peoples BK (2019) Mutualism or parasitism: partner abundance affects host fitness in a fish reproductive interaction. Freshw Biol 64: 174-182. doi: 10.1111/fwb. 13205

38. Sherley GH (1990) Co-operative breeding in riflemen (Acanthissitta Chloris) benefits to parents, offspring and helpers. Behaviour 112: 1-22. doi: 10.1163/156853990X00653

39. Soler JJ, Cuervo JJ, Møller AP, DeLope F (1998) Nest building is a sexually selected behaviour in the barn swallow. Anim Behav 56: 1435-1442. doi: 10.1006/anbe.1998.0938

40. Stiver KA, Wolff SH, Alonzo SH (2013) Sharing of potential nest sites by Etheostoma olmstedi males suggests mutual tolerance in an alloparental species. PLOS ONE 8: e56041 doi: 10.1371 /journal.pone.0056041

41. Sumasgutner P, Millán J, Curtis $O$, Koelsag A, Amar A (2016) Is multiple nest building an adequate strategy to cope with inter-species nest usurpation? BMC Evol Biol 16: 97. doi: 10.1186/s12862-0160671-7

42. Taborsky M (1994) Sneakers, satellites and helpers: parasitic and cooperative behaviour in fish reproduction. Adv Study Behav 23: 1-100. doi: 10.1016/S0065-3454(08)60351-4

43. Taborsky M (2001) The evolution of bourgeois, parasitic, and cooperative reproductive behaviors in fishes. J Hered 92: 100-110. doi: 10.1093/jhered/92.2.100 
44. Taborsky M (2009) Reproductive skew in cooperative fish groups: virtue and limitations of alternative modeling approaches. In: Hager R, Jones C (eds) Reproductive skew in vertebrates: proximate and ultimate causes. Cambridge University Press, Cambridge, pp 265-304. doi: $10.1017 /$ СB09780511641954.012

45. Theuerkauf J, Rouys S, Mériot JM, Gula R, Kuehn R (2009) Cooperative breeding, mate guarding, and nest sharing in two parrot species of New Caledonia. J Ornithol 150: 791-797. doi: 10.1007/s10336009-0400-8

46. Wallin JE (1989) Bluehead Chub (Nocomis leptocephalus) nests used by yellowfin shiners (Notropis lutipinnis). Copeia 4: 1077-1080. doi: 10.2307/1446006

47. Wallin JE (1992) The symbiotic nest association of yellowfin shiners, Notropis lutipinnis, and bluehead chubs, Nocomis leptocephalus. Environ Biol Fish 33: 287-292. doi: 10.1007/BF00005872 48. Hunt J, Hodgson D (2010) What is fitness, and how do we measure it? In: Westneat DF, Fox CW (eds) Evolutionary behavioral ecology. Oxford University Press, Oxford, UK

\section{Figures}

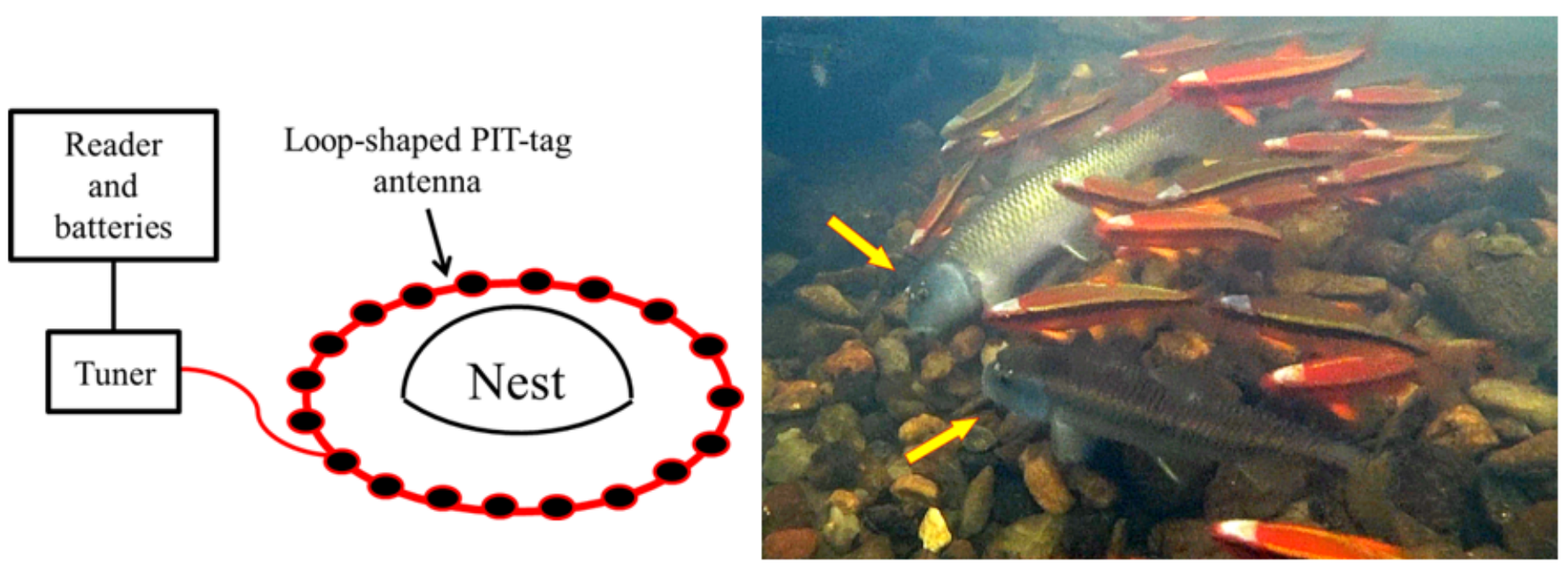

Figure 1.

\section{Figure 1}

Design of the loop-shaped PIT antenna to monitor male bluehead chub on nests (left). Photo showing two male bluehead chub (yellow arrows) and yellowfin shiner (red individuals) spawning on the nest (right). 


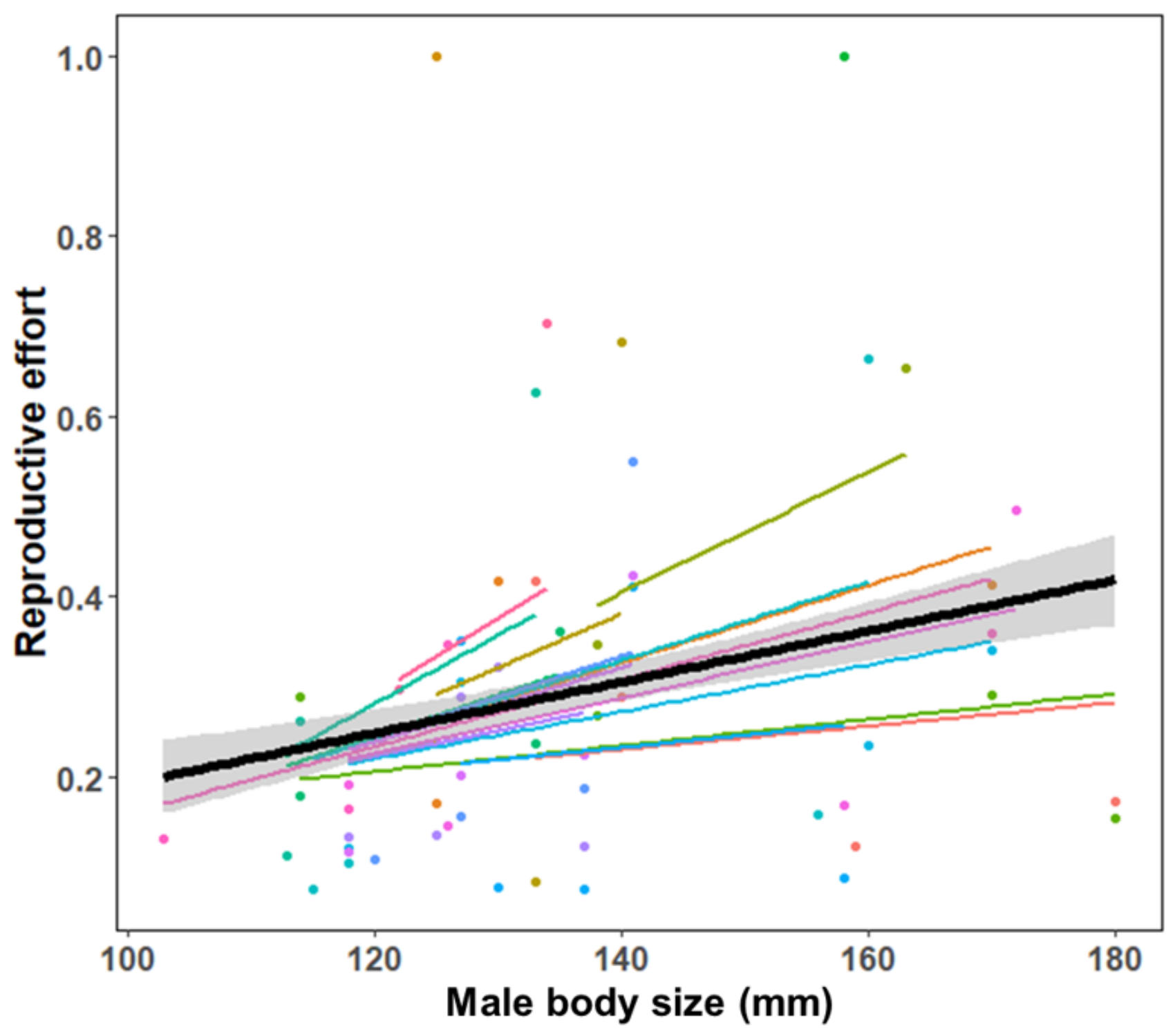

Figure 2.

Figure 2

Predicted relationships between male body size and reproductive effort (i.e., proportion of detections by PIT antennas on each nest). The black line indicates the mean overall response across nests and gray shading shows $95 \%$ confidence interval. Each line with different color represents a nest-specific pattern. 

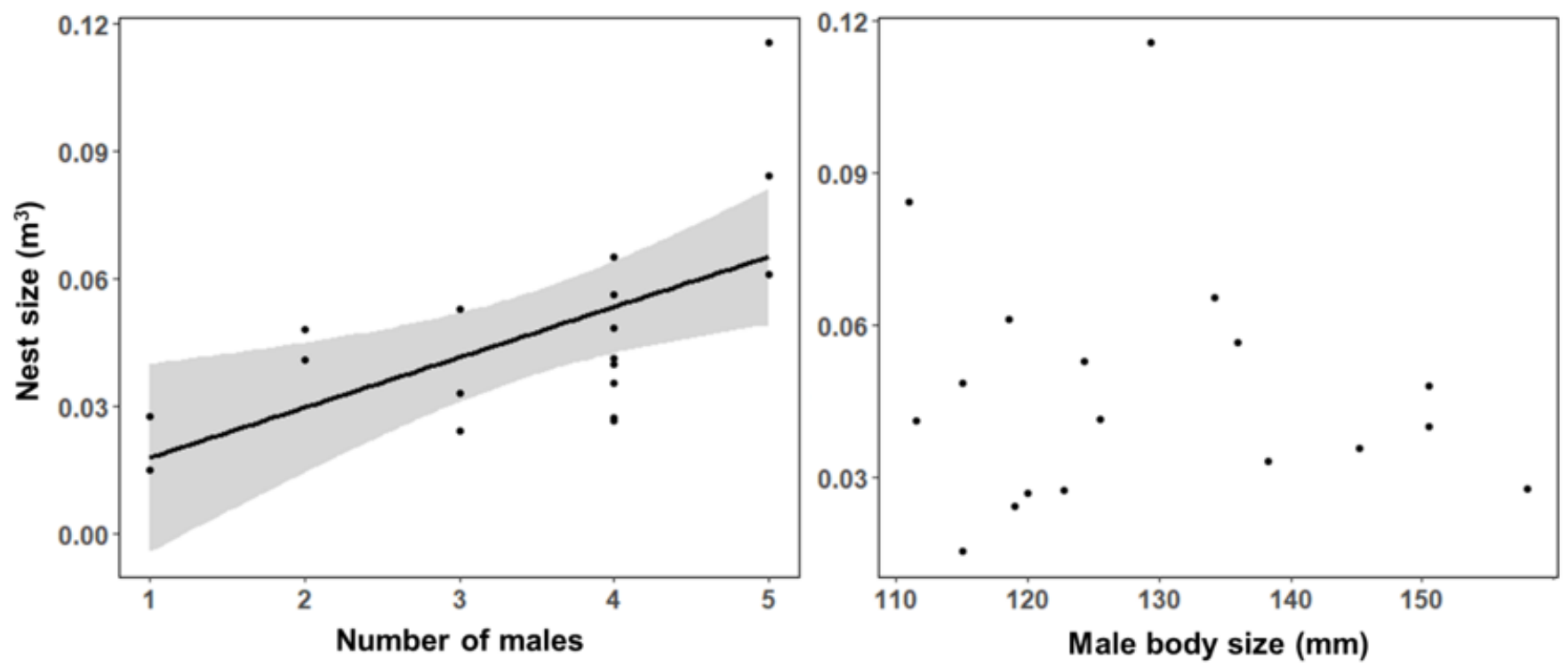

Figure 3.

\section{Figure 3}

Effects of the number and mean body size of males on nest size $(n=18)$. Black line indicates mean response, and gray shading shows $95 \%$ confidence interval. 
(a)
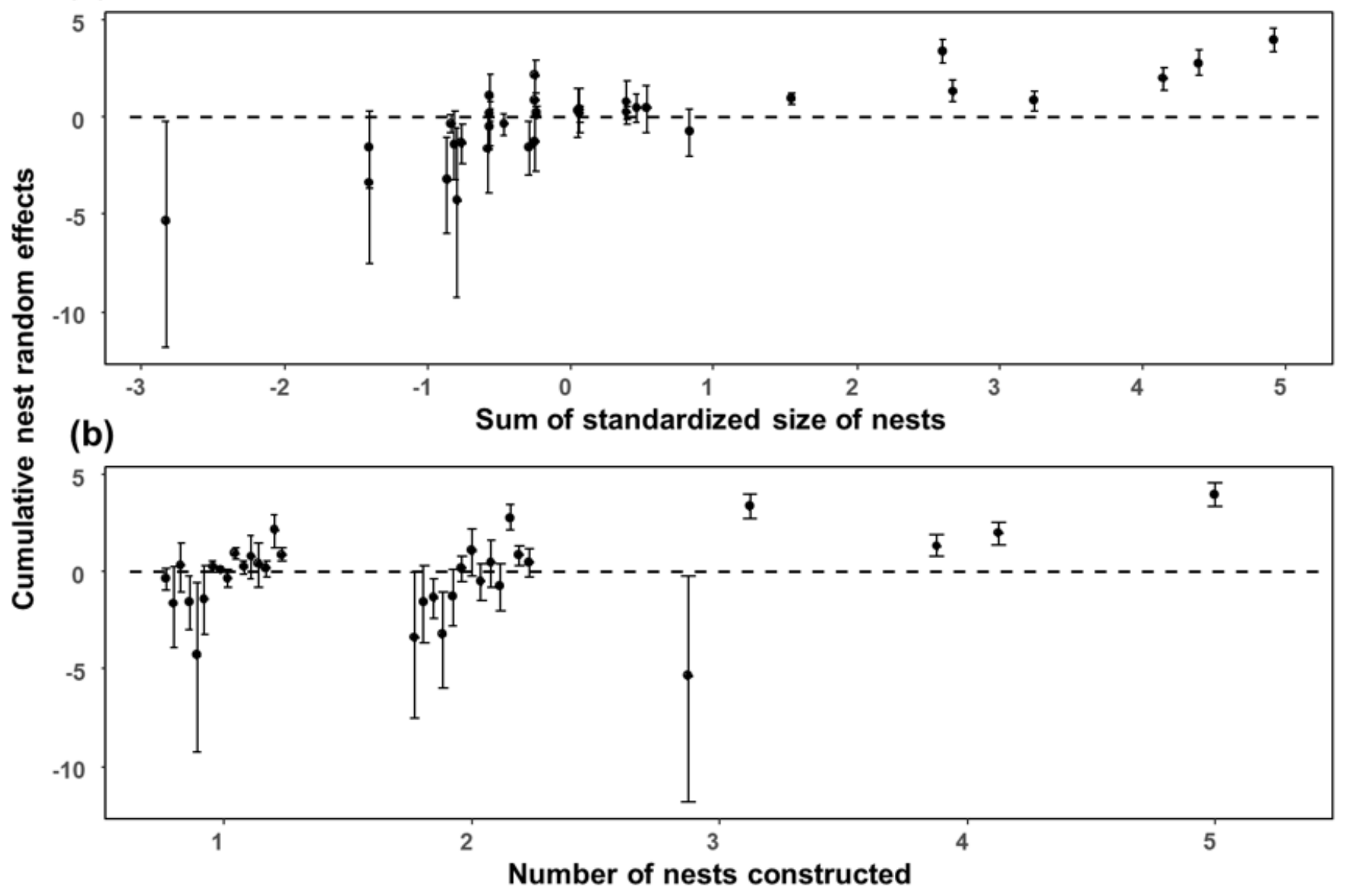

Figure 4.

Figure 4

The relationship between cumulative nest random effects $\left(\sum_{-}{ }_{j} w_{-} i, j a_{-} j\right)$, and (a) sum of standardized size of nests and (b) number of nests each male constructed. Bars and dots represent $95 \%$ posterior credible intervals and mean values, respectively. Estimates with $95 \%$ credible intervals that do not bound zero (dashed line) are considered statistically significant. 


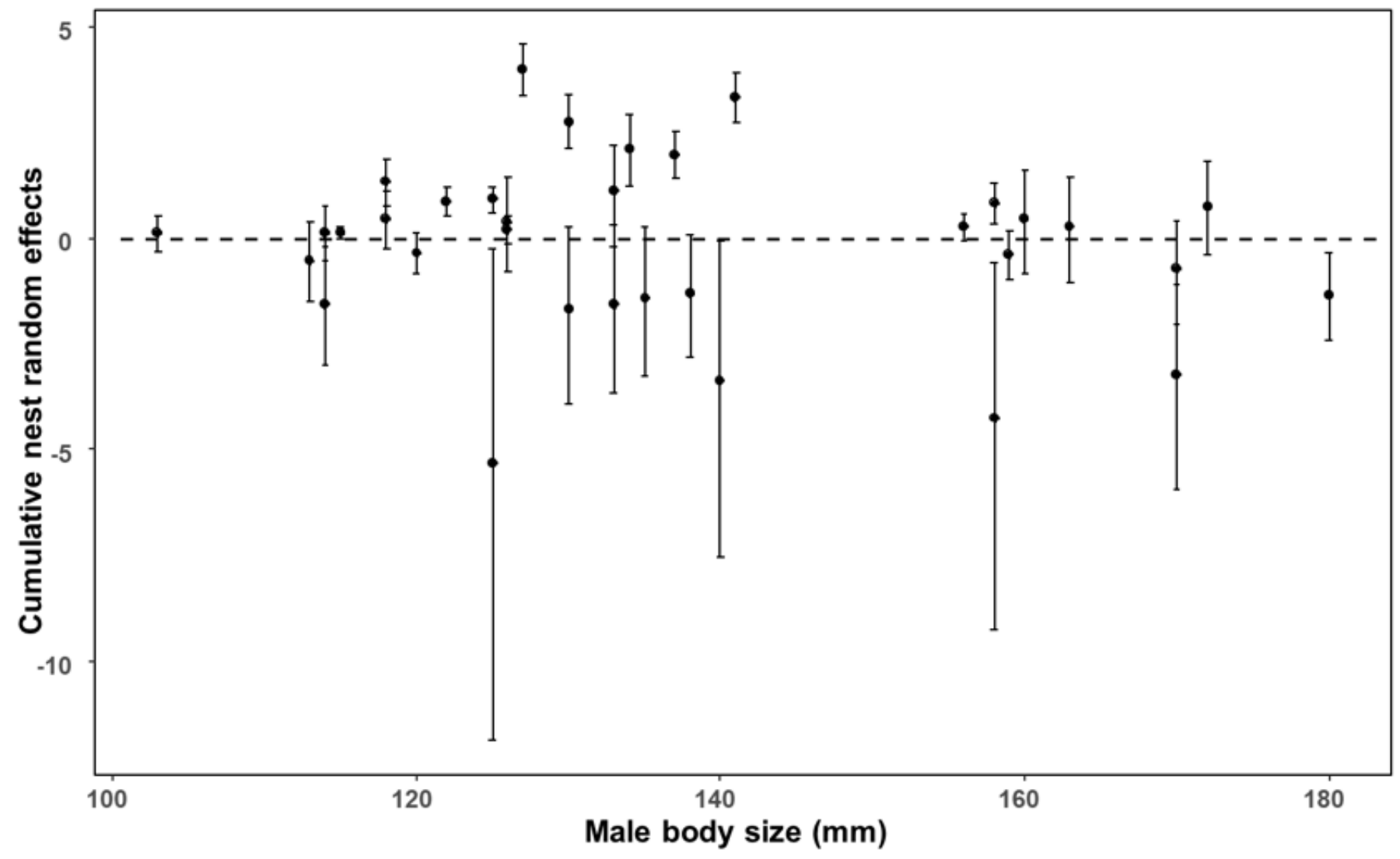

\section{Figure 5.}

\section{Figure 5}

Relationship between male body size and cumulative nest random effects ( $\left.\sum_{-}{ }_{j} w_{-} i, j a_{-} j\right)$ on reproductive success of 34 males. Bars and dots represent $95 \%$ posterior credible intervals and mean values, respectively. Estimates with $95 \%$ credible intervals that do not bound zero (dashed line) are considered statistically significant. The mean posterior cumulative nest random effects did not depend on male body size (Pearson correlation test: $r=-0.15, P=0.40$ ).

\section{Supplementary Files}

This is a list of supplementary files associated with this preprint. Click to download.

- SupplementaryMaterial20210513.docx 